\title{
Active Learning: A Prerequisite for Language Development in the Mixed Ability Class (MAC) of Engineering Students
}

\author{
Meenakshi Harraw Verma \\ (Invertis Institute of Engineering \& Technology, Bareilly, Uttar Pradesh, India) \\ doi:10.7575/aiac.alls.v.2n.2p.185
}

\begin{abstract}
Engineering students tend to pay more attention to their core subject classes rather than on an English language class. They all come from different social and academic backgrounds and their knowledge of English language varies from one another. A mixed ability group throws many challenges to an English language teacher teaching to a grown up or rather adult group of learners who always pre-define their interests and needs. The primary and the most important challenge in front of the language teacher teaching engineering students is - how to promote active learning in MAC situation? A language teacher to overcome the problems of a mixed ability classroom and promote active learning needs to adopt a number of strategies. The paper studies the MAC situation in an English language classroom of engineering students and makes an attempt to re-define methods for active learning - a prerequisite for language development in an engineering classroom.
\end{abstract}

\section{Defining mixed ability class}

A mixed ability class is a teaching system in which students having different abilities are taught together. These students differ not only in their learning abilities but in motivation, background knowledge, interest and learning style too. As they come from different social, cultural and educational backgrounds their personality, attitude and exposure also vary from one another drastically. Traditionally such group of students can be called a 'heterogeneous class'. In a mixed ability class of language, the teacher is expected to cater to the need of every individual to expedite learning. Every class is always a mixed ability class but with the globalization and new job opportunities English Language is expected to become everybody's cup of tea. The thrust has come to the language teacher to train every individual so that he can be recruited and can carry out different written and verbal official assignments with required proficiency in English. 


\section{Defining active learning}

Active learning means involving the learner actively in the process of learning. Active learning is advancement over passive learning which offers methods of engaging students in the learning process. Students do not learn simply by listening in the classroom. They have to read, understand, comprehend, reflect and interact with fellow students and teachers. Active learning provides scope for these aspects of learning in the classroom. It transforms the classroom process and culture, and contributes to students' learning speed. Active learning can be defined as 'learning by doing'. For effective language learning, the language teacher needs learners to participate actively in the language class. Students' active participation requires curiosity, interest, attention, and motivation. Only a curious student shall be interested in the class and pay attention to what the teacher says. Attention works like a stimulus, to which the learner responds. An effective teacher knows how to create and maintain the learners' attention in the classroom.

\section{Active Learning Methodology (ALM)}

Active Learning Methodology recognizes that the brain of a child can do wonders. It suggests that the learner should be actively engaged in the class activities and he should be given liberty to behave fearlessly. Same classrooms and same textbooks are used by the teacher to transform the brain of the child. In an English language classroom of engineering students, ALM can be adopted by using different techniques. Some of them are:

- Tasks should be so designed so as to promote group work, pair work, and individual work to involve the students.

- Along with the textbooks, supplementary materials should be used. For example if a student's knowledge of the basic skills of English language is poor, he should be provided with materials which help him/her develop the basic knowledge of the language, e.g. a storybook recommended for lower classes.

- Students should be allowed to interview one another and talk to the teacher in the classroom.

- Students should be guided to prepare some topics of their own.

- Promote creativity by using a variety of tasks. Keep the relevance of the task to them. For example - extempore speeches, group discussions, presentations and mock 
interviews are appreciated by engineering students as they find these tasks relevant to their needs as these tasks prepare them for future.

\section{Literature review}

Active Learning refers to several models of instruction that focus the responsibility of learning on learners. Bonwell and Eison popularized this approach to instruction. In their report to the Association for the Study of Higher Education (ASHE) they discussed a variety of methodologies for promoting active learning. Bonwell and Eison (1991) state that active learning strategies are comparable to lectures for achieving content mastery, but superior to lectures for developing thinking and writing skills. 'The practice with feedback' is the active learning component of the study. The researchers found that students who had practice with feedback had better performance and more positive attitudes than those students who did not have opportunities for practice. Chickering and Gamson (1987) suggest that students must do more than just listen. They must read, write, discuss or be engaged in solving problems. They must involve in higher order thinking tasks as analysis, synthesis and evaluation. According to Penner (1984) Active Learning Methodology is a modification of traditional lectures. During lectures also this technique can be adopted by allowing students consolidate their notes by pausing three times for two minutes each during a lecture. Students will learn significantly more information (Ruhl, Hughes \& Schloss 1987).

Mayer (2004) suggests that for learning students should be cognitively active rather than being behaviourally active. Anderson, Reder and Simon (1998), Gagné (1966), Kirschner, Sweller and Clerk (2006) argue that not sufficient literature is available to support the Active Learning Theory and according to them students who are actively involved with the material are more likely to recall information as argued by Bruner (1961).

Dee Fink (1999) has suggested Model of Active Learning. He says that all active learning activities involve some kind of experience or dialogue. The learner either learns by doing or by observing. During both these activities he is in some kind of dialogue either with himself or with others. In traditional teaching also he reads a textbook or listens to the teacher. This situation can be regarded as a partial dialogue. A more dynamic and active form is when the teacher initiates a Group Discussion activity in the class. This helps the teacher to find ways to involve more students in dialogue situation. Observation means watching or listening to somebody else. The act of observing may be: 
i) Direct - observing the real action directly; e.g., poverty

ii) Vicariously - Watching a movie on poverty

This shows that sufficient work has been done to define and identify the scope and application of Active Learning Methodology. I was influenced with the idea to experiment it in my class and feel satisfied with the positive results. It has been my observation that students take more interest in activity based classes rather than in theory classes which demand them to sit idly in the class providing the teacher a pivotal role. In active learning the teacher moves to the backdrop giving the hold of the class to the students. Target learners take the central place and are enthusiastic to participate. The teacher speaks less in this situation - only to initiate a task or in complex situations when students demand.

\section{How can students be actively involved?}

First principle that an English language teacher in an engineering classroom needs to practice on priority is to teach 'English for Specific Purpose'. Engineering students' aptitude is necessarily technical and their mindset looks for accuracy and relevance of every phenomenon they come across. In that case if the teacher does something which they assess of no or less use for them, they do not apparently take interest. As soon as the teacher introduces a task or exercise in an engineering classroom, students' start evaluating it. The teacher's ability lies in creating exercises or taking up tasks in such a way that the students react spontaneously to it. It has been observed that active participation of students can only be ascertained when the teacher is playing an active role of a catalyst in the class (Mazilu, 2004) i.e. the teacher has to be proactive to make the students active not only in the class but outside the class too as language learning continues beyond the boundaries of the classroom as well.

\section{Example Activity}

Target Learners: B. Tech I year students (Information Technology Branch)

Task: Interview someone who has similar qualification (B. Tech Information Technology) personally, telephonically or through e-mail. Ask relevant questions (Sample questions given below). Write the information accessed and then present it verbally in the class.

Questions/information to be accessed

i. In which capacity/designation, he/she is working.

ii. Nature of responsibilities assigned.

iii. Challenges he/she has to face at the workplace. 
iv. Types of meetings, he/she has to attend.

v. Types of meetings, he/she has to conduct.

vi. The difference between the above two situations.

vii. The growth prospects with the present job.

viii. Role of communication skills at the work place.

ix. Discuss his/her strategy to handle workplace conflicts.

x. Any significant change, he/she finds in them during this job.

Students were given freedom to talk face to face, on telephone or through e-mail. Use of different methods to access information was again discussed in the class to know the difference in the use of language. Obviously, a face to face talk involves different vocabulary from telephonic talk and so is true with the vocabulary used on e-mail.

\section{Objective}

The objective of this activity was to make the students aware of the positions they will be offered and of the nature of responsibilities they will be given during their job. This was to acquaint them with the practical work experience and relate to their present status of study, so that they can tune their minds to the future requirements and start working to bring significant changes required for their personal growth. At the same time, it was expected as well as predefined that they would interact and express themselves through language. That is how they will learn English by using it, which was their instructor's main objective, i.e., learning English for its use. The expected output included practicing asking questions to get required information, improving vocal skills-pronunciation and language use, improving existing knowledge and enhancing confidence.

\section{Observation}

The task was given to 60 students of B. Tech I year students in Information and Technology Branch. The target learner group hailed from different social and academic backgrounds. They also varied in their level of existing knowledge and proficiency in English language. They have been studied till class XII in ICSE (Indian Certificate of Secondary Education), CBSE (Central Board of Secondary Education) or State Board Schools. ICSE and CBSE affiliated schools provide education of all subjects except language through English medium while state board schools teach through the regional language (Hindi in Uttar Pradesh). These schools follow bilingual method and structural approach to teach English. It is obvious that 
ICSE and CBSE students have a better hand on communicative and written English. State Board students may further be divided into two groups-i) students from the urban areas, ii) students from the rural areas. Rural area students may be defined as the disadvantaged learners on the basis of their poor knowledge of English.

It was a challenging task to prepare all the students for the task under reference. In the first year most students are not aware of the nature of responsibilities they have to carry out at their work place and they feel excited to know that. The teacher can play the instrumental role and become a facilitator to guide them to know this. Here, the remarkable point is that their curiosity has been utilized by the teacher. The basic instinct to know the unknown is to be exploited to make the learners more confident in language use. Of course, this is an exercise for students who have attained four basic skills of language learning - reading, writing, listening and speaking. Students from the rural background were not proficient users of English language. They were assisted by the teacher and their peer group as well to complete the task. First of all, their psychological preparation was taken care of by the teacher. They were motivated to accept the task willingly and made to believe confident to complete the task.

\section{Teacher's role}

A language teacher's responsibility in an engineering classroom is more than the responsibility of any other teacher for the same course as language is the only medium through which students can understand and express their technical subjects. Language is the medium which helps them in building confidence and self esteem. They know but are unable to express - this feeling hampers their confidence and further learning. Therefore, a language teacher needs to be more specific in:

\section{i) Knowing all students individually}

A language teacher, as he/she is supposed to teach the language skills must know each student personally. This helps the teacher understand the strengths and weaknesses of his/her students. While teaching and assigning tasks, he/she should be vigilant to judge the personal traits and attributes. This helps the teacher to guide the students correctly. For example, if the

teacher comes to know that a student is interested in English songs, he/she can take the help of lyrics of those songs to improve student's language skills. If he/she observes that a particular student is more interested in sports, he can be guided through the vocabulary used 
for different sports. He can be taught to describe or to compare or to narrate.

\section{ii) Understanding their social and cultural background}

Every student comes from the society to which the teacher also belongs; in spite of the fact that students belong to different classes of the society. In a multicultural and multilingual country like India, they come from different social and cultural backgrounds. While speaking the same language, their values and practices are different. They follow different religions. They have been brought up differently.

A teacher needs to understand this so that he/she can justify in the classroom. Not only from the point of view of the teaching content and style but also from the point of view of language use. He/she needs to understand that every student carries self esteem which has the influence of his/her family traditions, so no such words or sentences should be used which can embarrass the student.

\section{iii) Developing a user-friendly classroom for self learning}

A user-friendly classroom means creating a situation where students can learn vicariously. The teacher introduces the task, engages the students doing that task and behaves like an observer making the students feel that he/she is a part of the class - one who can make mistakes as they do. This helps students to open up to the teacher. They are able to share their problems in the language use. When they get solutions to remove their problems they develop faith upon the teacher which in turn boosts up their morale.

\section{iv) Developing tasks to cater to individuals}

As every individual differs in his/her abilities, a teacher's job is to identify the skill and cater to the one's need. One's learning abilities depend upon one's inherited intellectual capacity: some students can learn faster than the others. Memory also plays an important role in learning. Memory can be defined as the capability to recall. If the learnt matter is not retained by the mind, it means it has been forgotten. A teacher needs to take care and devise teaching techniques so that the taught items are retained in the mind of the learner for a long time. A teacher can make the language learning permanent by using following methods-

a) Language items should be taught in association with the examples from the real life situation.

b) Material to be taught should be meaningful to the students. 
c) Material should be so organized as to be related to the previous knowledge of the students.

d) Learners must be provided intervening time between the first learning and the subsequent learnings.

\section{v) Evaluating periodically to know their progress}

Periodic evaluation is important to assess the development in the language use. Summative and formative evaluation processes should be adopted carefully by the teacher, and students should be judged on different language aspects including its suprasegmental features.

The teacher should observe and find out the learner's basic desire as well as purpose to learn a language. The teacher must try to enhance the motivation of the learner and keep him actively involved in the language class, guide him so that he uses his learning outside the classroom confidently. An English language teacher of engineering students needs to be careful about the deviations and failures of the learner. At such point of time, the teacher's role becomes very important. A combination of the teacher's educational training and personal attributes affect the learner's attitude to language learning. The teacher's behaviour and skill to deal with his/her learners can promote their concentration and as a result intensify their efforts to learn.

\section{Role of motivation}

According to Gardner and Lambert (1972), motivation for language learning is of two kinds -

i) Instrumental

ii) Integrative

If the learner learns the language to fulfil his professional needs or occasional purpose like travelling to a foreign country - the motivation is instrumental. However, if he is willing to share the social values and get intimated to the culture and philosophy of that country, the motivation is integrated. Learning English language by engineering students is completely instrumental. They do so to satisfy the demand of the professional world. To get a good job, they cannot do with the knowledge of English language. Learners who have integrated motivation to learn English language show better results in comparison to those who have instrumental motivation. A learner with integrated motivation is energised throughout the

process of learning whereas a learner with instrumental motive more often is seen getting depressed and losing confidence during the activities. He may learn some language items 
perfectly but fail in many. Curriculum designers and teachers must keep this factor in mind while planning English language classes for engineering students. Selection and sequencing of language items must be done in a way that can sustain learners' interest and the teacher must acquire skill to keep the students motivated throughout.

\section{Problems and recommendations}

A mixed ability class of engineering students throws many challenges to the teacher - firstly, what to do in or out the class and how to design meaningful set of active learning activities? seem to be the greatest challenges for the English language teacher of engineering students as he/she is teaching to students who are self aware adults with thinking abilities to decide what is relevant for them. Here, the psychology and attitude of the learners have to be recognized and the curriculum has to be so designed that suits to the needs of the target group. Students may not participate, or use higher order thinking or learn sufficient content. Further-

Problem (P): It may be difficult for the teacher to know each student personally.

Recommendation (R): If it is difficult to know each student personally, the teacher must monitor each student to know if his/her needs are being addressed or not and also whether language learning is taking place. The teacher should keep in mind that students are individuals and language is individual specific, hence their problems related to language use have to be different from one another. Therefore, they need to be guided individually. I have observed that some students tend to make more mistakes in the use of tenses. While others can use wrong pronouns, articles and prepositions, some of them are weak in spellings, thus they need guidance on this skill.

P: Some students learn faster and some learn slowly. Some of them may find the task easy, others may find it difficult.

R: The teacher must adapt the task according to the needs and proficiency level of the learners.

P: Some of the students may find the task interesting and some may find the same task boring.

R: The task 
P: Some of the students get many turns to speak in the class, other may not (willingly or may be due to less attention from the teacher)

R: The teacher needs to keep an eye on the passive participants and prefer to engage them in the activities more often than the fluent speakers. This will help them change their mindset of going passive in the class when they know that anyhow they have to participate if it is their turn. It is not possible to escape in any case.

P: While proficient learners handle the task willingly and more confidently, less competent learners may find it difficult to speak in the target language due to various reasons ranging from their interest, knowledge and confidence.

R: Students prefer to be paired or grouped with their friends in the class. If the teacher finds it effective, it could be done. But preferably the teacher must group the weaker students with competent students as in the professional environment, not necessarily one has to communicate with friends only. One has to communicate with strangers or persons from other departments who are the part of the same organization but not known to them. They will be hesitant in such situations; therefore, they should be exposed to such situations. Always being in their comfort zone is not going to help them out; they have to be brought out of that to behave naturally in a real life professional situation.

Participation of the higher level students should be used as the model for the lower level students e.g. difficult questions are generally answered by the higher level students. Those answers can be listened by the lower level students and then repeated in the class.

Activities such as debates, group discussions, mock interviews, presentations, extempore speeches and role plays can be practiced in an English language class of engineering students. Students get opportunities to discuss current, social and general affairs. Their discussion and arguments with one another help them develop language skills for communicative purposes. Strong students come up with better results in comparison to weak students. Strong students can be defined as students with better language proficiency and exposure to social environment. They tend to be more participative in the class. Such students' knowledge and skill should effectively be used. What they speak is to be listened by the weak students. Thus, strong students prove to be a resource in the classroom for the teacher. 
The teacher needs to recognize students at the elementary level. In a MAC situation there happens to be 2-6 students per class who lack proficiency in basic language skills. They have to be uplifted to the average level so that they are able to communicate in real life situations which are the prime objective of learning English language by engineering students. They are to be engaged more often than the strong students. While due to faster learning speed strong students practice more and complete more advanced individual tasks, weak students stick to the beginner exercises. For example, in a group discussion situation, fluent speakers give their opinions confidently and use their argumentative skills to win the situation whereas a weak students has to be made participative by teaching him/her to listen to other speakers and form his own opinion and then is guided to say 'yes, I agree with you.' Or 'You may be right, but I don't agree with you'. He is taught small sentences to be used in such situations. For an extempore speech strong students are given topic on the spot while weak students are given topic 10 minutes before and they are asked to sit and discuss with strong students and write what they want to speak. In their first effort, they may need to take the help of the paper, if so they are given a second chance and in case the teacher feels necessary, they can be given a third chance as well on the same day. In their later efforts they are not allowed to refer to their written notes. This exercise has to be repeated several times on the subsequent days and it helps a weaker student improve.

\section{Conclusion}

In spite of various challenges and problems, the need for taking risk to implement Active Learning Methodology for English language learning in an engineering classroom cannot be denied. It can be adopted as an educational reform by the teachers. English language teachers teaching in engineering institutes must be trained to design and implement tasks which cater to the needs of individual students. Those who are taking initiatives in this direction must be encouraged for their efforts. Language is learnt for instant use; therefore, students have to be provided with simulation exercises which will train them to behave naturally in real life situations. Of course, it demands high level of dexterity and creativity on the part of the teacher as it requires more time for preparation. In lack of required material and resources, teachers have to utilize their own creativity to design the task according to the needs of their target learners. It will help students increase awareness and become decision makers. Without active participation language learning cannot be ascertained. The present study suggests the effective use of Active Learning methodology to overcome the problems of a mixed ability class of engineering students to teach them real language use. 


\section{References}

Anderson, J. R., Reder, S., Lynne, M., Herbert, A. K., Ericsson, A. \& Glaser, R. (1998). Radical constructivism and cognitive psychology. In D. Ravitch. Brookings papers on education policy (pp. 227-278). Washington, D.C.: Brookings Institute Press.

Bonwell, C., Eison, J. (1991). Active learning: Creating excitement in the classroom. AEHE-ERIC Higher Education Report No.1. Washington, D.C.: Jossey-Bass. ISBN 1-87838-00-87.

Bruner, J. S. (1961). The act of discovery. Harvard Educational Review 31 (1): 21-32.

Chaudhary, Sheeresh. (2002). The sociolinguistic context of English language teaching in India. In S. Kudchedkar (Ed.). English Language Teaching in India. Orient Longman, Chennai.

Chickering, Arthur W., \& Gamson, Zelda F. (1987). Seven principles for good practice. AAHE Bulletin 39: 3-7. ED 282 491. 6 pp. MF-01; PC-01.

Gagné, R. (1966). Varieties of learning and the concept of discovery: A critical appraisal. In Shulman, L. S. \& Keislar, E. R. (Eds) Learning by discovery: A critical appraisal. Chicago: Rand McNally and Co.

Gardner, R.C., \& Lambert, W.E. (1972). Attitudes and motivation : Second language learning. Newbury House.

Kirschner, P. A., Sweller, J., \& Clark, R. E. (2006). Why minimal guidance during instruction does not work: an analysis of the failure of constructivist, discovery, problem-based, experiential, and inquiry-based $\begin{array}{llllll}\text { teaching. } \quad \text { Educational Psychologist } 41 & \text { (2): } 75-86 . & \text { Retrieved from }\end{array}$ http://www.cogtech.usc.edu/publications/kirschner_Sweller_Clark.pdf.

Fink, L. (1999). Active learning. Retrieved from http://www.honolulu.hawaii.edu/intranet.

Mayer, R. (2004). Should there be a three-strikes rule against pure discovery learning? The case for guided methods of instruction. American Psychologist 59 (1): 14-19. doi:10.1037/0003-066X.59.1.14.

Mazilu, S.A. (2004). The teacher as catalyst. BETA-IATEFL. Retrieved from http://www.betaiatefl.org/962/blog-publications.

Penner, Jon G. (1984). Why Many College Teachers Cannot Lecture. Springfield, Ill. Charles C. Thomas.

Ruhl, Kathy L., Hughes, Charles A., \& Schloss, Patrick J. (1987). Using the Pause Procedure to Enhance Lecture Recall. Teacher Education and Special Education 10: 14-18.

Spitzberg, Brian H., Cupach, William R. (1984). Interpersonal communication competence. Sage Publications Inc.

Sweller, J. (1988). Cognitive load during problem solving: Effects on learning. Cognitive Science 12 (1): $257-$ 285. doi:10.1016/0364-0213(88)90023-7. 